\title{
Statistical analysis and simulation modelling of the belowground food webs of two winter wheat management practices
}

\author{
J. C. MOORE*, H. J. C. ZWETSLOOT \& P. C. DE RUITER \\ Institute for Soil Fertility Research, P.O. Box 30003, NL 9750 RA Haren, Netherlands
}

Received 12 February 1990; accepted 7 May 1990

\begin{abstract}
Soil food webs from conventional and integrated management practices at the Lovinkhoeve experimental site (Noordoostpolder, Netherlands) were analysed using multivariate statistical procedures and simulation modelling, so as to identify patterns in species interactions and material transfers.

Cluster analysis, canonical discriminant analysis and canonical correspondence analysis of the dynamics of biomass- $\mathrm{N}$ of functional groups within the food webs indicated that the webs could be compartmented into categories of functional groups based on food choice and trophic level. The degree of compartmentalization depended on management practice. Consumers of fungi were separated in time from consumers of bacteria under the integrated management practice whereas little separation was observed under conventional practice.

Simulation modelling was used to estimate the flux rates of nitrogen among functional groups within the food webs. The modelling demonstrated that more flow occurred in the integrated plot than in the conventional plot. More material flow occurred in the upper 10 $\mathrm{cm}$ of the integrated plot than in the $10-25 \mathrm{~cm}$ layer, whereas there was no such difference in the conventional plot. This effect may be due to the differences in the tillage practice on each plot.
\end{abstract}

Keywords: food webs, cluster analysis, canonical discriminant analysis, canonical correspondence analysis, nitrogen flux rates

\section{Introduction}

The soils of the Noordoostpolder, Netherlands, were reclaimed from the former Zuiderzee between 1936 and 1942, and subsequently developed for agriculture. In 1953 the Lovinkhoeve experimental farm was established and since 1964 the soils

\footnotetext{
* Visiting scientist from the Natural Resource Ecology Laboratory, Colorado State University, Fort Collins, CO 80523, USA.

Communication No 32 of The Dutch Progamme on Soil Ecology of Arable Farming Systems.
} 
have been under continuous cultivation with six- and four-year crop rotations that included winter wheat, sugar beets, barley and potatoes. The food webs from the Lovinkhoeve presented here are from the winter wheat rotations under a low-input integrated management practice and a high-input conventional management practice (Brussaard et al., 1988).

The architectures of the two food webs are similar in all respects except for the absence of predatory collembola in the conventional plot. The food web presented in Figure 1 (integrated practice) was drawn in a similar fashion as the food web described by Hunt et al. (1987) for the North American Shortgrass Steppe. The food web consists of five trophic positions (I-V, bottom of Fig. 1):

Position I - detritus and primary production,

Position II - primary decomposers and herbivores, i.e., bacteria, fungi (saprophytic), phytophagous nematodes,

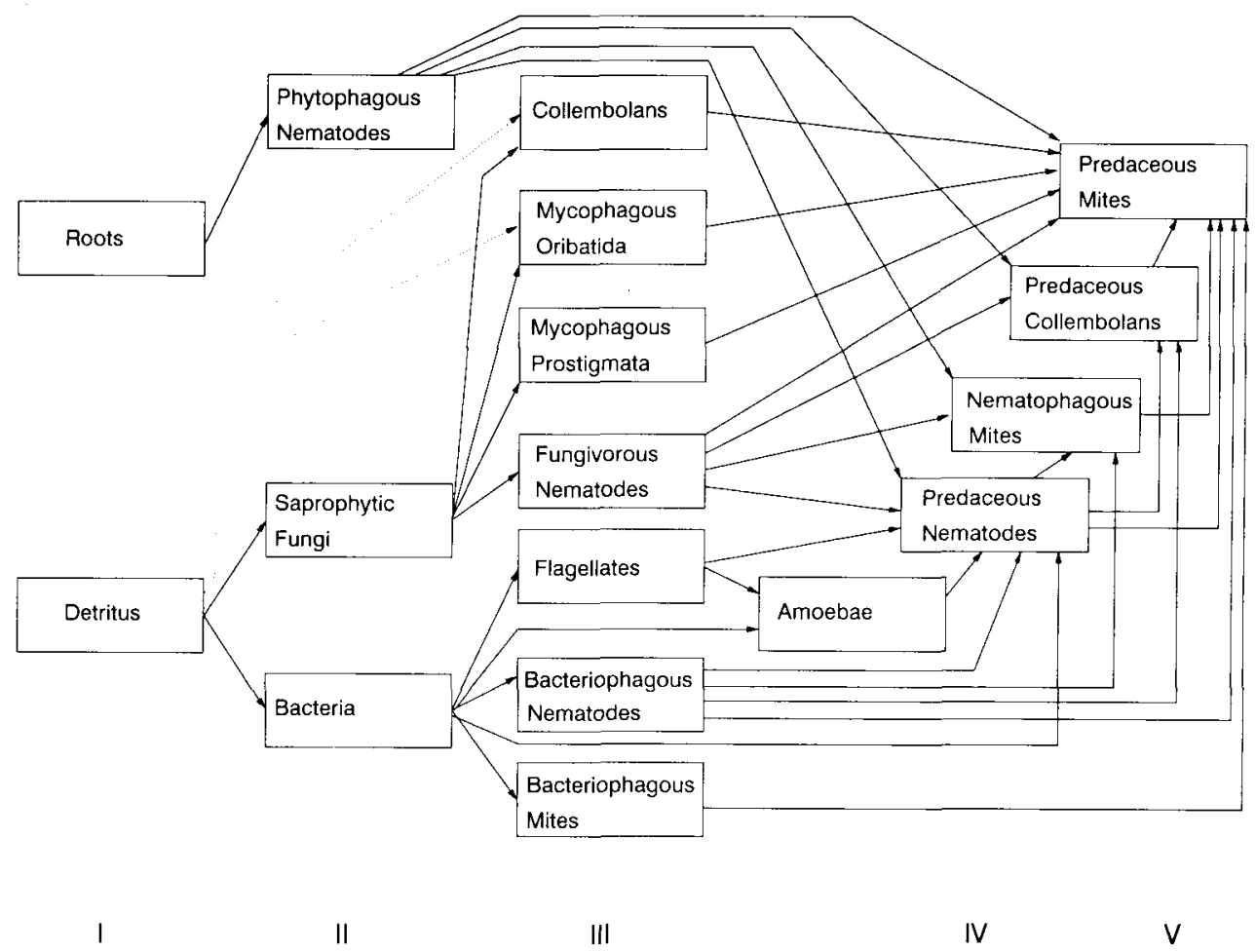

Fig. 1. Connectedness diagrams of the soil food webs of the Lovinkhoeve Experimental Farm, Marknesse, Netherlands (winter wheat). The food web presented is from the integrated plot. The food web from the conventional plot is similar to that from the integrated plot, except that predatory collembola are not present in the conventional plot. The dashed arrows indicate unquantified, potential feeding relationships. The 'Mycophagous Oribatida' represent mites that chew fungal hyphae with chelate mouthparts and 'Mycophagous Prostigmata' represent mites that pierce fungal hyphae with their mouthparts; these two groups also include some other groups than Oribatida or Prostigmata, respectively. 
Position III - consumers of bacteria and fungi, e.g., collembola, mycophagous mites and nematodes, protozoa and bacteriophagous nematodes,

Position IV - intermediate predators, i.e., predaceous nematodes and nematophagous mites,

Position V - top predators, i.e., predaceous mites and collembola.

The food webs do not include some potentially important functional groups of which no field data were available, such as algae, root pathogens, annelids, mycophagous protozoa and nematophagous fungi. An analysis of the dynamics of the biomass of the individual functional groups is presented by Brussaard et al. (1990). In the present paper we use multivariate statistical analysis and simulation modelling to find patterns in the way functional groups interact and matter is transferred within the food webs. Three statistical methods were applied to the biomass data:

(1) cluster analysis (Sokal \& Michener, 1959) was used to find out which functional groups show approximately similar dynamics,

(2) canonical discriminant analysis (Hotelling, 1936) was applied to categories of functional groups, based on energy source and trophic position, in order to test whether these categories differ significantly with respect to their biomass dynamics, (3) canonical correspondence analysis (ter Braak, 1986) was used to identify and visualize the relations between seasons and biomass.

Simulation modelling (after Hunt et al., 1987, and O' Neill, 1969) was used to estimate the flows of nitrogen among functional groups. The estimates of the flows of nitrogen were used to study the dynamics of nitrogen flows originating from the different energy sources within the food webs: roots, bacteria and fungi.

\section{Materials and methods}

\section{Site description}

The soil of the Lovinkhoeve is a calcareous silt loam with $\mathrm{pH}-\mathrm{KC1}$ 7.5. Annual precipitation at the site is between $650-800 \mathrm{~mm}$. The results presented in this paper are from two management practices - integrated and conventional. Integrated management differs from the conventional practice mainly in reduction of $\mathrm{N}$ fertilizer application to 50-65\% of the recommended dosages in the conventional practice (from 130-285 to $65-170 \mathrm{~kg} \mathrm{ha}^{-1} \mathrm{yr}^{-1}$, depending on crop), a reduction of pesticide application and a reduction of soil tillage $(20-25 \mathrm{~cm}$ plough in conventional, 12-15 cultivator or plough in integrated). In addition to these differences, the upper $20 \mathrm{~cm}$ of soil of the conventional plot has an organic matter content of $2.3 \%$, whereas that of the integrated management plot is $2.8 \%$. For further details, see Kooistra et al. (1989).

Prior to 1985, the conventional and integrated plots had different crop rotations. The conventional plots were under a six-year rotation, whereas the integrated plots were under a six-year rotation with two-year's ley. During the 1984 and 1985 growing seasons, both plots were under winter wheat and sugar beets, respectively. Since 1985 , both plots have been under the same four-year crop rotation of winter wheat, 
sugar beets, barley and potatoes. The data presented here are from the 1986 winter wheat crop.

\section{Statistical methods and simulation modelling}

Cluster analysis (Sokal \& Michener, 1959; Gower \& Ross, 1969) was used to form clusters of functional groups that showed similar dynamics in biomass- $\mathrm{N}$. The biomass- $\mathrm{N}$ of each functional group within the Lovinkhoeve food webs was estimated on 5 sampling dates (methods: Brussaard et al., 1990). The data were standardized by dividing the biomass- $\mathrm{N}$ estimate of a functional group on a given date by the sum of the total biomass- $\mathrm{N}$ estimates for that functional group over all five sampling dates. These standardized biomass- $\mathrm{N}$ estimates for each functional group were used as input for the cluster analysis. With this technique, all the functional groups were initially considered to be unique clusters and then combined to form aggregate clusters in a step-wise fashion. At each step, the two clusters with the closest Euclidean distance are merged to form a new cluster. Separation between clusters is based on an arbitrary distance $\delta$ : the distance between each pair of groups in a cluster is less than or equal to $\delta$, whereas the distances between clusters are greater than $\delta$. Therefore, the results of a cluster analysis depend on the choice of $\delta$, on the distance measure (e.g. Euclidean, City Block), and on the choice of the method for merging clusters. We used two methods for merging clusters: the average link method as developed by Sokal \& Michener (1959) and the single link method (Gower \& Ross, 1969). Both methods resulted in the same set of clusters, which is an indication of a rather strong cluster structure.

A canonical discriminant analysis (CDA, Hotelling, 1936) was used to visualize and test the differences between the collections of functional groups, classified into one of six categories according to energy source and trophic position (Fig. 1). Bacteria, fungi and root-feeding nematodes (trophic position II) were left as separate categories. Consumers of bacteria that occupy trophic position III were grouped as bacterial feeders, and consumers of fungi that occupy trophic position III were grouped as fungal feeders. Functional groups that occupy trophic positions IV and $\mathrm{V}$, and obtain their energy from consumers of roots, bacteria and fungi, were grouped as predators. The standardized biomass estimates used in the cluster analysis were used as input for the CDA. With the CDA, canonical variables (linear combinations of the proportions of biomass for each date) were determined that best summarized differences among the six categories of functional groups. After computing the canonical variables, a multivariate analysis of variance (MANOVA, teststatistic Wilk's Lambda) was conducted to determine whether the six categories showed statistically significant differences. If the MANOVA was significant $(P<$ 0.05 ), Hotelling's $T^{2}$ (Hotelling, 1936) was computed from the pairwise Mahalanobis distances between pairs of categories of functional groups to determine significant differences in dynamics. Hotelling's $T^{2}$ can be regarded as the multivariate extension of the univariate Student's $t$ test for the differences of means of two populations.

Canonical correspondence analysis (CCA, ter Braak, 1986) was used to identify 
and visualize the relations between sampling dates and the biomass- $\mathrm{N}$ of the functional groups. Canonical correspondence analysis relates species to explanatory variables, e.g., humidity, soil temperature and organic matter content under the assumption that these relationships are unimodal (ter Braak, 1986). CCA is a multivariate extension of weighted averaging and can generate biplots of species scores (in our case, scores of functional groups) on axes that are linear combinations of the set of explanatory variables provided. For the sake of comparison with the canonical discriminant analysis and the cluster analysis, we restricted the analysis to sampling date as the single explanatory variable in order to examine whether the observed patterns can be explained by contrasts between seasons.

A simulation model was used to estimate the rates at which biomass/energy is transferred among functional groups. The model can be run either as a $\mathrm{C}$ or an $\mathrm{N}$ model. We chose to run it as an $\mathrm{N}$ model and used the biomass- $\mathrm{N}$ estimates of the functional groups as input for the model. The nitrogen flux rates were calculated as follows. Assuming that the functional groups are at steady state, production must balance loss of material $(M)$ due to natural death and predation. The feeding rate $(F)$ by one functional group can be calculated (Hunt et al., 1987):

$$
F=\frac{M}{A e \times P e}
$$

where $A e$ is the fraction of consumption being assimilated and $P e$ the fraction of assimilated energy allocated to production. If dynamics are to be included, the decrease or increase in biomass of the predator $(\mathrm{d} E / \mathrm{d} t)$ has to be added to the material losses (O’Neill, 1969):

$$
F=\frac{M+\mathrm{d} E / \mathrm{d} t}{A e \times P e}
$$

If predators feed on more than one prey type, then both the preference of the predator for a given prey and the relative abundance of the prey in the predator's diet have to be considered. The consumption rate of the $i$ 'th prey $\left(f_{i}\right)$ can then be calculated (O’Neill, 1969):

$$
f_{i}=\frac{W_{i} \times e_{i} \times F}{\Sigma W_{i} \times e_{i}}
$$

where $W_{i}$ is the preference factor for the $i$ 'th prey and $e_{i}$ the density of the $i$ 'th prey. The calculations started with flux rates between top predators and their prey, since for those predators only the mortality caused by natural death needs to be known. All flux rates could then be calculated back throughout the food web ending with those from bacteria, fungi and roots. Apart from the biomass- $\mathrm{N}$ data, the model requires information on the diets, feeding preferences, $\mathrm{C} / \mathrm{N}$ ratios, production and assimilation efficiencies, and birth and death rates of the functional groups. We assumed that the parameters used for the shortgrass food web calculations (for references see Hunt et al., 1987) are not specific for a particular environment. Therefore, we used the same set of parameters, except for the death rates of the nematodes which were observed to be higher (approximately seven times) in 
Lovinkhoeve soil (L. A. Bouwman, pers. comm.). These high death rates are caused by nematophagous fungi, which are not included in the food web description.

Before presenting the results, a word of caution is in order. Since the replication at the Lovinkhoeve was nested within the plots, and the history of the plots was different for each management practice, we did not have true replications of the food web as a whole and the management practice is confounded with plot history. The functional groups within the categories, as used in the CDA and CCA, represent replications, which may not be appropriate. Therefore, the analyses presented here constitute a case study and any reference to the results should reflect this.

Fraction of Total Biomass

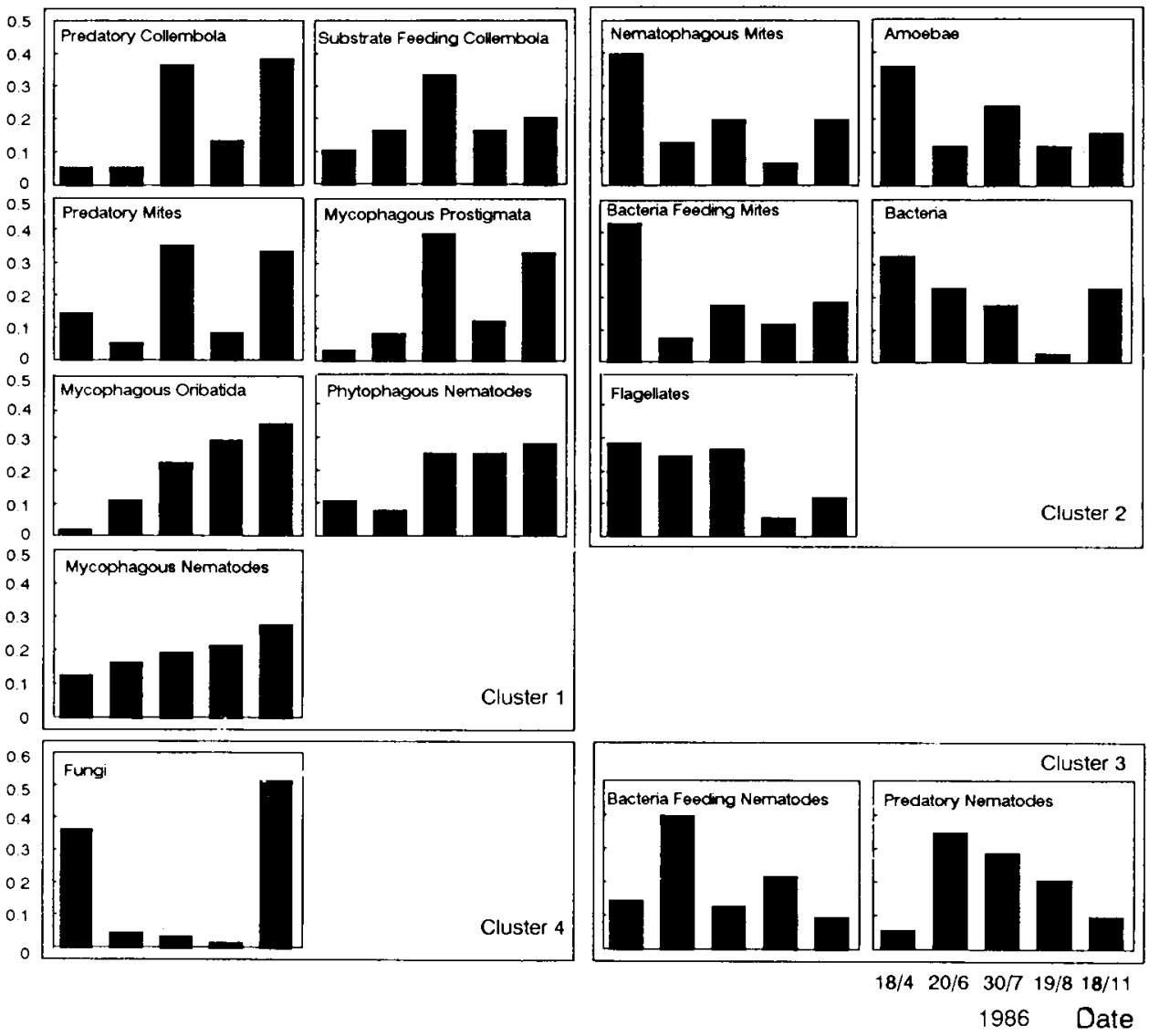

Fig. 2. Bar graphs of the fraction of total biomass- $\mathrm{N}$ collected over the five sampling dates for each functional group, within the integrated plot. 


\section{Results}

\section{Cluster analysis}

The cluster analysis indicated that there were three clusters in the conventional plot and four in the integrated plot. For the integrated plot, the dynamics of the functional groups in each cluster are presented in Figure 2 and the dendrograms for both plots are presented in Figure 3. For the conventional plot, fungi, bacteria and amoebae separated from the other functional groups, with no apparent pattern in the memberships of the remaining two clusters. For the integrated plot, fungi separated from all other functional groups. The remaining clusters contained either fungal feeders and predators (Cluster 1) or bacteria, bacterial feeders and predators (Cluster 2 and 3). In conclusion, the cluster analysis suggested that the dynamics of functional groups in the integrated plot was dependent on the types of food they consumed. This relationship did not hold in the conventional plot, in that the bacteria and fungi were exhibiting similar dynamics but distinct from most of their consumers.

\section{Canonical discriminant analysis}

Biplots of the first and second canonical variables for the integrated and conventional plot illustrate the patterns found in the cluster analysis (Fig. $4 a, b$ ): in the integrated plot, consumers of bacteria and fungi exhibited different dynamics, whereas the predators showed dynamics common to both consumer groups. In the
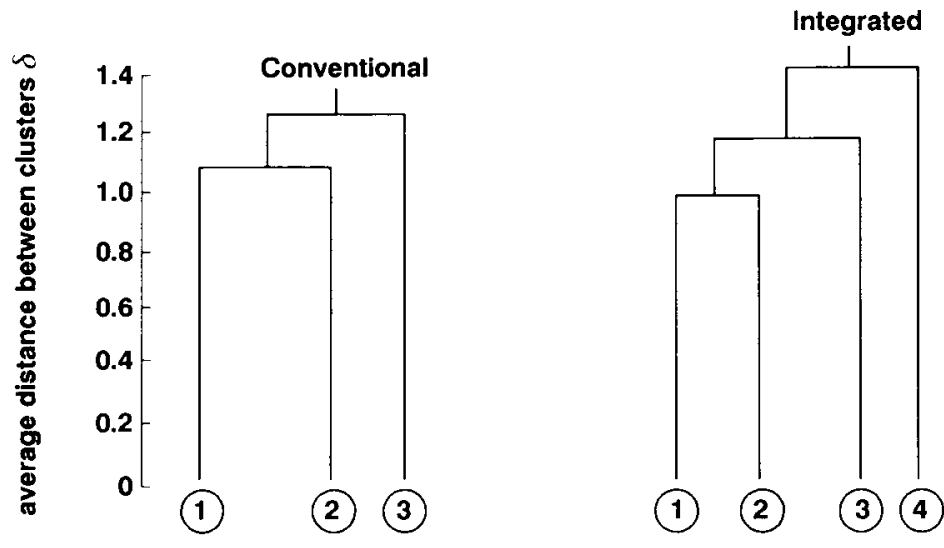

Fig. 3. Average-linkage dendrogram for distances between proportions of biomass-N on the sampling dates for the functional groups in the conventional and integrated plots. For the conventional plot, the functional groups within each cluster are: Cluster No 1 - bacteria, fungi, amoebae; Cluster No 2 - bacteriophagous mites, mycophagous oribatida, nematophagous mites; Cluster No 3 - collembola, mycophagous prostigmata, phytophagous nematodes, predatory nematodes, bacteriophagous nematodes, fungivorous nematodes, predatory mites, flagellates. For the integrated plot, see Fig. 2. 


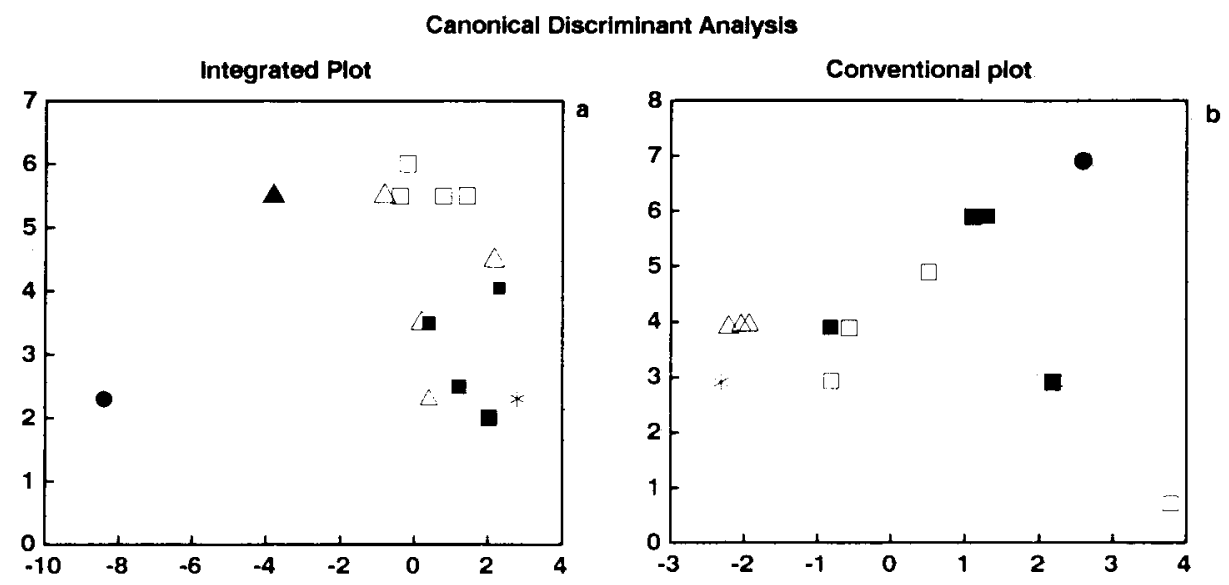

Canonical Correspondence Analysis

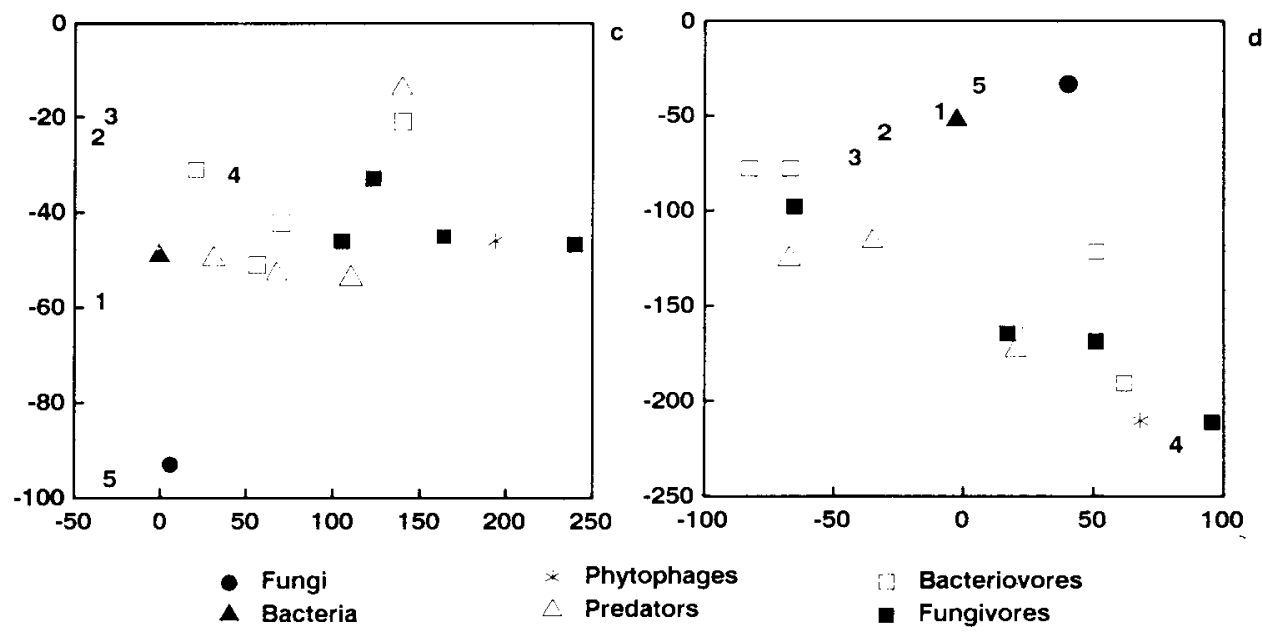

Fig. 4. Scatter plots of the first and second canonical variables of the canonical discriminant analysis (CDA) and the canonical correspondence analysis (CCA) for the categories of functional groups based on food choice and trophic level. (a) CDA, integrated plot; (b) CDA, conventional plot; (c) CCA, integrated plot; (d) CCA, conventional plot. Numbers in the CCA biplots refer to sampling date: $1=18$ April; $2=20$ June; $3=30$ July; $4=19$ August; $5=18$ November.

conventional plot, such a pattern could not be identified. The MANOVA indicated that there were differences among the categories of functional groups within the integrated plot $(P<0.05)$ but not within the conventional plot. Therefore, we restricted our use of Hotelling's $T^{2}$ to the intgerated plot. For the integrated plot, Hotelling's $T^{2}$ indicated that the bacteria and fungi exhibited different dynamics, and both groups differed from all consumers (Table 1). The dynamics of the bacterial feeders were different from those of the fungal feeders. Root feeders differed from 
Table 1. Matrix indicating which categories of functional groups were different from one another in the canonical discriminant analysis (CDA). Test based on Hotelling's $T^{2}$, where $T^{2} \sim F(1, n 1+n 2-2)$.

\begin{tabular}{lllllll}
\hline Category of functional groups 1 & 1 & 2 & 3 & 4 & 5 & 6 \\
1. Bacteria & - & & & & & \\
2. Fungi & $* *$ & - & & & \\
3. Bacteriovores & $* *$ & $* *$ & - & & \\
4. Fungivores & $* *$ & $* *$ & $* *$ & - & - \\
5. Phytophages & $* *$ & $* *$ & $*$ & ns & ns \\
6. Predators & $* *$ & $* *$ & ns & ns & - \\
\hline
\end{tabular}

1 The number in the row for each category of functional groups corresponds to the number in the column.

${ }^{*}=P<0.05,{ }^{* *}=P<0.01, \mathrm{~ns}=$ not significant.

fungi, bacteria, and bacteriovores, but not from fungivores or predators. Predator dynamics did not differ from the dynamics of consumers of fungi, bacteria or plant roots.

\section{Canonical correspondence analysis}

The biplots produced by the CCA showed a pattern which bore a resemblance to the patterns generated by the CDA (Fig. 4): in the integrated plot the fungivores were separated from the bacteriovores, indicating different dynamics. To provide a statistical basis for these differences in the integrated plot, Hotelling's $T^{2}$ was calculated from the Mahalanobis distances between the groups, with the same drawback as with the CDA: no real replicates were available to calculate the variances within categories of functional groups (Table 2). This test revealed the same pattern of statistically significant differences among the six categories of functional groups, but these differences were less pronounced than in the CDA. This was to be expected, as CDA maximized the differences between pre-designated aggregations of func-

Table 2. Matrix indicating which categories of functional groups in the integrated plot were different from one another in the canonical correspondence analysis. Test based on Hotelling's $T^{2}$, calculated from the first $p$ axes $(p=4)$, where $T^{2} \sim F\left(p, \sum n_{i}-p-I\right)$.

\begin{tabular}{|c|c|c|c|c|c|c|}
\hline Category of functional groups 1 & 1 & 2 & 3 & 4 & 5 & 6 \\
\hline 1. Bacteria & - & & & & & \\
\hline 2. Fungi & $*$ & - & & & & \\
\hline 3. Bacteriovores & $\mathrm{x}$ & $* *$ & - & & & \\
\hline 4. Fungivores & $*$ & $* *$ & $\mathrm{x}$ & - & & \\
\hline 5. Phytophages & $*$ & $* *$ & $\mathrm{x}$ & ns & - & \\
\hline 6. Predators & * & $* *$ & ns & ns & $\mathbf{x}$ & - \\
\hline
\end{tabular}

IThe number in the row for each category of functional groups corresponds to the number in the column.

$\mathrm{x}=P<0.10,^{*}=P<0.05,^{* *}=P<0.01$, ns $=$ not significant. 
tional groups, whereas CCA only related the distribution of functional groups to the explanatory variables provided without using prior information about grouping. In the conventional plot, the distance between bacteriovores and fungivores was not significant. The CCA biplots also relate sampling date to the distribution pattern of the groups (Fig. 4), although the interpretation of this relation is not very straightforward. For example, in the biplot of the integrated plot (Fig. 4c) the fungi are near sampling date 5 on which the fungi reached their maximum density, showing a contrast between summer (sampling dates 2, 3, and 4) and autumn (sampling date 5), whereas spring (sampling date 1) was intermediate (see also Fig. 2).

Table 3. Relative importance of the bacteria, fungi, and root energy source (in percentages) of the functional groups in the integrated and conventional plot.

\begin{tabular}{|c|c|c|c|c|c|c|}
\hline & \multicolumn{3}{|c|}{ Integrated plot } & \multicolumn{3}{|c|}{ Conventional plot } \\
\hline & bacteria & fungi & root & bacteria & fungi & root \\
\hline Bacteria & 100 & & & 100 & & \\
\hline Fungi & & 100 & & & 100 & \\
\hline Phytophagous nematodes & & & 100 & & & 100 \\
\hline Bacteriophagous nematodes & 100 & & & 100 & & \\
\hline Fungivorous nematodes & & 100 & & & 100 & \\
\hline Predatory nematodes & 88 & 1 & 11 & 94 & 2 & 4 \\
\hline Oribatida & & 100 & & & 100 & \\
\hline Prostigmata & & 100 & & & 100 & \\
\hline Bacteriophagous mites & 100 & & & 100 & & \\
\hline Nematophagous mites & 78 & 3 & 19 & 86 & 5 & 9 \\
\hline Predatory mites & 45 & 44 & 11 & 33 & 64 & 3 \\
\hline Substrate-feeding collembola & & 100 & & & 100 & \\
\hline Predatory collembola & 78 & 3 & 19 & - & - & - \\
\hline Amoebae & 100 & & & 100 & & \\
\hline Flagellates & 100 & & & 100 & & \\
\hline
\end{tabular}

Table 4. The biomass estimates of bacteria and fungi, and flux rates from the bacterial and fungal energy source; per depth: $0-10 \mathrm{~cm}$ and $10-25 \mathrm{~cm}$. Data are standardized per $10 \mathrm{~cm}$ depth: biomass $(\mathrm{kg} \mathrm{N}$ per ha per $10 \mathrm{~cm}$ ); flux rate $(\mathrm{kg} \mathrm{N}$ per ha per $10 \mathrm{~cm}$ per year).

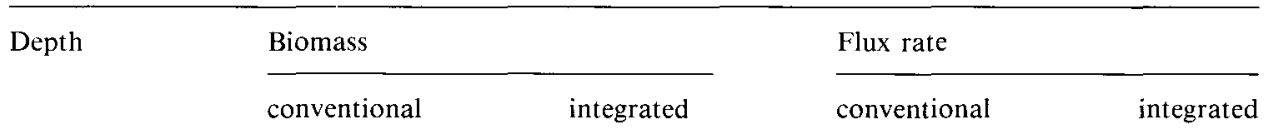

\section{Bacteria}

$\begin{array}{rllll}0-10 \mathrm{~cm} & 61 & 93 & 30 & 55 \\ 10-25 \mathrm{~cm} & 68 & 76 & 30 & 25\end{array}$

Fungi

\begin{tabular}{|c|c|c|c|c|}
\hline $0-10 \mathrm{~cm}$ & 1.14 & 2.09 & 0.70 & 0.85 \\
\hline $10-25 \mathrm{~cm}$ & 1.33 & 1.71 & 0.70 & 0.55 \\
\hline
\end{tabular}




\section{Analysis of nitrogen flux rates}

The nitrogen flux rates estimated with the simulation model were sorted according to the basic energy sources of the food web: bacteria (detritus), fungi (detritus) and roots (primary production), as a means of summarizing the collective activity of consumers and predators in the food web (Table 3 ). It appeared that the relative importance of the different energy sources for the polyphagous predators do not reflect the great differences in the biomass- $\mathrm{N}$ of the energy sources (the ratio bacteria:fungi:root feeders is approximately 10:1:0.01). Subsequently we calculated the total flux rates derived from the bacterial and fungal energy sources. The ratio of the nitrogen flux rates from the bacteria and fungi was similar to the ratio of the bacterial and the fungal biomass (Table 4). This is not a trivial result, since the calculations of the flux rates depended on the density of the consumers rather than on density of bacteria or fungi. However, the flux rates showed greater spatial heterogeneity than the biomass estimates (Table 4, Fig. 5). In the conventional plot, flux rates

\section{Integrated Plot}
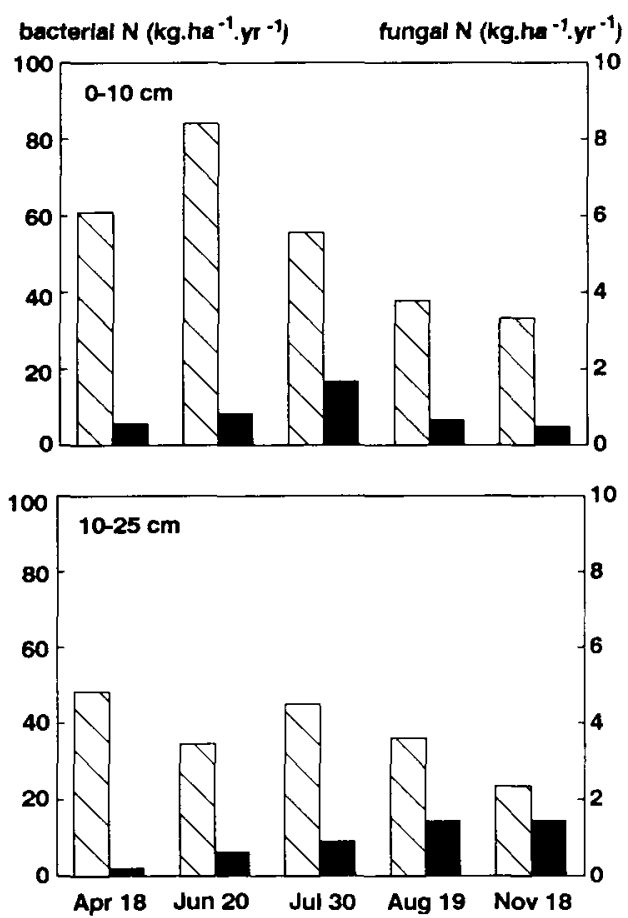

Conventional Plot
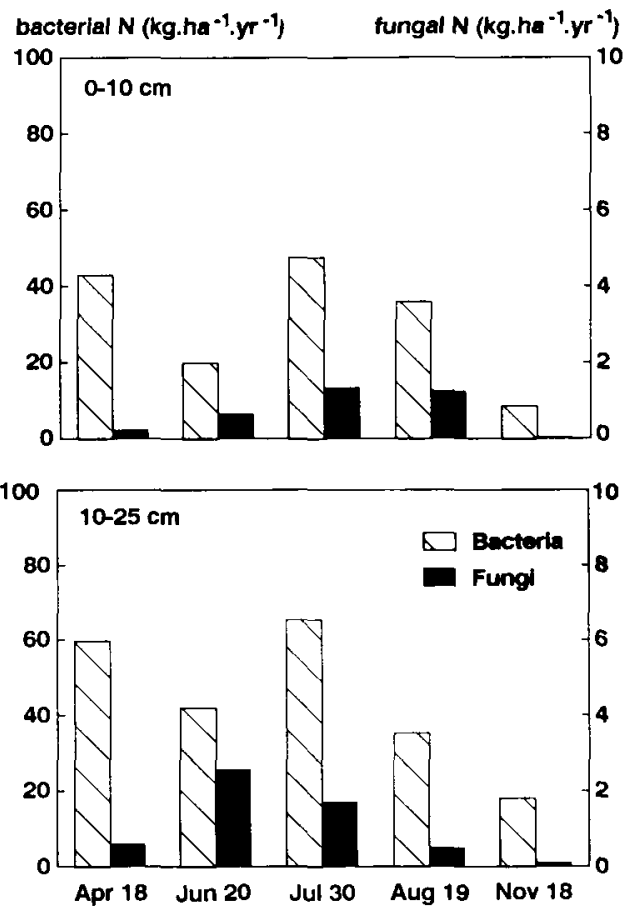

Fig. 5. Bar graphs of the cumulative $\mathrm{N}$ flux $\left(\mathrm{kg} \mathrm{N} \mathrm{ha-1}^{-1} \mathrm{yr}^{-1}\right)$ from the bacterial and fungal energy source for the conventional and integrated plot. The upper graphs represent the $0-10 \mathrm{~cm}$ depth, while the lower graphs represent the $10-25 \mathrm{~cm}$ depth. The estimates in the $10-25 \mathrm{~cm}$ depth were not standardized to a $10 \mathrm{~cm}$ increment like the estimates in Table 4. 
from bacteria and fungi ( $\mathrm{kg} \mathrm{N}$ per ha per $10 \mathrm{~cm}$ per year) did not appear to differ between depth, whereas in the integrated plot the flux rates in the top layer $(0-10$ $\mathrm{cm}$ ) clearly exceeded the rate in the lower layer $(10-25 \mathrm{~cm})$. This result is coinciding with differences in depth of soil tillage: $12 \mathrm{~cm}$ cultivator in the integrated plot and $20 \mathrm{~cm}$ plough in the conventional plot, and the distribution of organic matter: higher organic matter content in the integrated plot concentrated in the upper layer, and lower levels in the conventional plot homogeneously distributed between the two layers (Brussaard et al., 1988).

\section{Discussion}

The analysis presented in this paper constitutes a case study and conclusions should be formulated with caution, especially for the following reasons. There were no true replications of the food webs, nor of the management practices, and the management practices were confounded with plot history. The functional groups within the categories of functional groups, as used in the CDA and CCA, were considered as replications. All analyses are based on the biomass estimates of the functional groups, and the outcome of the analyses is very sensitive to the accuracy of these data. For some important groups (i.e. bacteria, fungi, protozoa) the methods to estimate biomass carry considerable uncertainties.

The analysis of the Lovinkhoeve food webs presented here suggests that functional groups with similar food sources may exhibit similar dynamics. In the integrated plot, with the strongest evidence of temporal clustering of functional groups, this clustering appeared to be based more on food source rather than on taxonomy. For example, the bacteriophagous mites had dynamics in common with amoebae, flagellates, and bacteria rather than with other groups of mites. Bacteriophagous nematodes showed closer affinity to other bacteriovores, while fungivorous nematodes clustered with fungivorous mites and collembola. The predators (functional groups that occupy trophic positions IV and V) appear to span the range of dynamics of their prey (Figs 3 and 4). The separation of the consumers of bacteria and fungi in time observed in the integrated plot may be due to several factors. Bacteria and fungi differ in their rates of growth and their responses to environmental variables, e.g. moisture, temperature, and disturbances within soil (Moore \& Hunt, 1988; AllenMorley \& Coleman, 1989). Consumers of bacteria and fungi may simply be responding to changes in the abundance of their food source.

The estimates of nitrogen flux rates supported the indication that the decomposer subsystems within the integrated and conventional plot are dominated by the bacterial energy source. This dominance of bacteria may be reflecting the history of the Lovinkhoeve soils. Bacteria and their consumers may have simply established in the site more readily than the fungi and their consumers (M. Christensen, pers. comm.). The levels of bacterial and fungal biomass- $\mathrm{N}$ and the flux rates of nitrogen originating from fungi and bacteria were higher in the integrated plot than in the conventional plot. The higher biomass and flux rates in the integrated plot over the conventional plot are probably due to differences in the organic matter content of the soils (Brussaard et al., 1988; Kooistra et al., 1989). 
The analysis of the nitrogen flux rates by depth indicated that in the conventional plot there was no difference between the top $10 \mathrm{~cm}$ and the $10-25 \mathrm{~cm}$ layer for the flux rates originating from the bacterial and the fungal energy source (Table 4, Fig. 5 ), whereas in the integrated plot proportionally more material flow occurred in the upper $10 \mathrm{~cm}$ than in the $10-25 \mathrm{~cm}$ layer. The differences in the depth distributions of the flux rates between the management practices and within the integrated plot is probably related to the depth of tillage for each practice: $20 \mathrm{~cm}$ in the conventional plot and $12 \mathrm{~cm}$ in the integrated plot.

For agricultural systems, Elliott \& Coleman (1988) suggested that more efficient use of agroecosystems may be achieved via reduced tillage to maintain optimal soil structure, reduced inputs of biocides, and less intensive management in order to better manage microbial populations. An objective of the research efforts by Elliott \& Coleman (1988) and Brussaard et al. (1988) is to manage microbial populations in order to attune nitrogen dynamics to plant growth. To this end, in addition to understanding microbial dynamics, the dynamics of the micro- and mesofauna should also be studied in view of their significant contribution to mineralization (Clarholm, 1985; Ingham et al., 1985; Hunt et al., 1987; Moore et al., 1988). These efforts are by necessity whole-systems approaches, and the techniques outlined here may assist in untangling the network of feeding interactions that constitute the mineralization process.

\section{Acknowledgements}

We wish to thank the Directorate for Agricultural Research of the Dutch Ministry of Agriculture, Nature Management and Fisheries, the International Agricultural Centre (Wageningen, Netherlands, Dr K. Harmsen and the US Department of Energy for their support of J. C. Moore during his stay at the Institute for Soil Fertility Research, Haren (Netherlands). We thank L. Brussaard, J. Hassink, K. B. Zwart and L. A. Bouwman for their contribution of data, time and discussion, J. A. van Veen, G. Lebbink, M. van Noordwijk, J. Bloem, P. de Willigen, E. T. Elliott, H. W. Hunt, and M. Christensen for discussion, and F. Sluiman for preparing the data.

This work was supported by the Netherlands Integrated Soil Research Programme.

\section{References}

Allen-Morley, C. R., \& D. C. Coleman, 1989. Resilience of soil biota in various food webs to freezing perturbations. Ecology 70: 1127-1141.

Braak, C. J. F. ter, 1986. Canonical correspondence analysis: a new eigenvector technique for multivariate direct gradient analysis. Ecology 67: 1167-1179.

Brussaard, L., J. A. van Veen, M. J. Kooistra \& G. Lebbink, 1988. The Dutch programme on soil ecology of arable farming systems. I. Objectives, approach and some preliminary results. Ecological Bulletins (Copenhagen) 39: 35-40.

Brussaard, L., L. A. Bouwman, M. Geurs, J. Hassink \& K. B. Zwart, 1990. Biomass, composition and temporal dynamics of soil organisms of a silt loam soil under conventional and integrated management. Netherlands Journal of Agricultural Science 38: 283-302. 
Clarholm, M., 1985. Interactions of bacteria, protozoa, and plants leading to mineralization of soil nitrogen. Soil Biology and Biochemistry 17: 181-187.

Elliott, E. T. \& D. C. Coleman, 1988. Let the soil work for us. Ecological Bulletins (Copenhagen) 39: 23-32.

Gower, J. C. \& G. J. S. Ross, 1969. Minimum spanning trees and single linkage cluster analysis. Applied Statistics 18: 54-64.

Hotelling, H., 1936. Relations between two sets of variates. Biometrika 28: 321-377.

Hunt, H. W., D. C. Coleman, E. R. Ingham, R. E. Ingham, E. T. Elliott, J. C. Moore, S. L. Rose, C. P. P. Reid \& C. R. Morley, 1987. The detrital food web in a shortgrass prairie. Biology and Fertility of Soils 3: 57-68.

Ingham, R. E., J. A. Trofymow, E. R. Ingham \& D. C. Coleman, 1985. Interactions of bacteria, fungi, and their nematode grazers: Effects on nutrient cycling and plant growth. Ecological Monographs 55: 119-140.

Kooistra, M. J., G. Lebbink \& L. Brussaard, 1989. The Dutch programme on soil ecology of arable farming systems. II. Geogenesis, agricultural history, field site characteristics and present farming systems at the Lovinkhoeve experimental farm. Agriculture, Ecosystems and Environment 27: 361-387.

Moore, J. C. \& H. W. Hunt, 1988. Resource compartmentation and the stability of real ecosystems. Nature 333: 261-263.

Moore, J. C., D. E. Walter \& H. W. Hunt, 1988. Arthropod regulation of micro- and mesobiota in belowground detrital food webs. Annual Review of Entomology 33: 419-439.

O'Neill, R. V., 1969. Indirect estimates of energy fluxes in animal food webs. Journal of Theoretical Biology 22: 284-290.

Sokal, R. R. \& C. D. Michener, 1959. A statistical method for evaluating systematic relationships. University of Kansas Scientific Bulletin 38: 1409-1438. 